\title{
LITERATURA E HISTÓRIA: EXPRESSÕES FICCIONAIS OU REAIS?
}

\author{
Cristian Paula Santana \\ Mestranda pela UFGD \\ paulasantana1957@hotmail.com \\ Leoné Astride Barzotto \\ Professora Doutora da UFGD \\ leoneastridebarzotto@gmail.com
}

\section{RESUMO}

Viso, neste artigo, relacionar Literatura, História e Memória através dos conceitos ligados à metaficção historiográfica e à pós-modernidade. Para maior eficácia, proponho, ao invés de uma revisão conceitual, buscar as teorias diretamente nas obras literárias. Para tanto, utilizarei como base as obras São Bernardo (1994) de Graciliano Ramos e A hora da estrela (1998) de Clarice Lispector para refletir sobre a metaficção; o conto Teorema (1970) de Herberto Helder para pensar a história e Um cinturão (1981) de Graciliano Ramos para discorrer acerca da memória.

Palavras-chave: Literatura, História, Memória.

INTRODUÇÃO

\begin{abstract}
In this article, I will relate Literature, History and Memory through the concept of historiographic metafiction and postmodernity. For greater efficiency, I propose, instead of a conceptual revision, to present the theories directly in the literary works. To do so, I will use as basis the works of São Bernard (1994) by Graciliano Ramos and The Hour of the Star (1998) by Clarice Lispector to speculate on metafiction; the short story Teorema (1970) by Herberto Helder to think about history and Graciliano Ramos's Um cinturão (1981) to reflect upon memory.
\end{abstract}

Keywords: Literature, History, Memory.

Quando o português chegou Debaixo duma bruta chuva Vestiu o índio Que pena! Fosse uma manhã de sol O índio tinha despido O português. Oswald de Andrade 
História e Literatura, duas categorias totalmente diferentes? Ou apenas distintas maneiras de expressar a realidade? Quais as relações entre elas? Em que medida a literatura está inserida na história? E em que medida a história está inserida na literatura? Expressam a realidade ou a ficção? É possível uma relação igualitária entre essas duas categorias? E a Memória? Qual o seu papel na literatura e na história? Há uma verdade expressa na memória? Vamos refletir sobre essas questões ao longo deste texto.

Pretendo neste artigo estabelecer uma relação entre Literatura, História e Memória por meio dos conceitos ligados à metaficção historiográfica e à pós-modernidade. Para isso, apresento, no lugar de uma revisão conceitual, a busca das teorias diretamente nas obras literárias. Assim, usarei como suporte as obras São Bernardo (1994) de Graciliano Ramos e A hora da estrela (1998) de Clarice Lispector para refletir sobre a metaficção; o conto Teorema (1970) de Herberto Helder para pensar a história e Um cinturão (1981) de Graciliano Ramos para discorrer acerca da memória.

No primeiro tópico discorrerei sobre o conto Teorema e a sua relação com a história de Portugal, mais especificamente na ficcionalização da história. Em um segundo momento, refletirei a respeito dos romances São Bernardo de Graciliano Ramos e A hora da estrela de Clarice Lispector para pensar as metaficções presentes nas obras.

Por fim, debaterei acerca do processo memorialístico invocando os teóricos Paul Ricoeur, José Carlos Sebe Bom Meihy e Marcio Seligmann-Silva aplicando suas teorias no conto Um cinturão de Graciliano Ramos.

\section{A HISTÓRIA FICCIONALIZADA}


Ah, quem escreverá a história do que poderia ter sido? Será essa, se alguém a escrever, a verdadeira história da humanidade ${ }^{1}$.

Para discorrer sobre a ficcionalização da história, utilizarei como suporte o conto Teorema de Herberto Helder, poeta português. Como base teórica serão usados os textos de Adriana Ortega Clímaco, História e ficção em Santa Evita; de Beatriz Sarlo, A paixão e a exceção e de Cecil Jeanine Albert Zinani o texto História da Literatura: questões contemporâneas.

Por muito tempo, história e literatura foram vistas como duas categorias opostas. Enquanto a história estava em seu estandarte protegida pela verdade a ficção se refugiava na imaginação. Uma era preterida pela outra. Havia uma hierarquia entre esses dois gêneros. Mas, atualmente, isso vem mudando. Estudiosas como Adriana O. Clímaco, Beatriz Sarlo, Cecil Zinani e Linda Hutcheon vêm quebrando essas barreiras que limitam tanto a história quanto a literatura. Outros teóricos também vêm inovando e trazendo contribuições por meio de reflexões sobre a memória e a sua importância para a construção da história.

Cada teórica e cada teórico vêm, à sua maneira, revelando as fragilidades do pensamento dicotômico: história é verdade, ficção é invenção, portanto, mentira. O pós-modernismo rompe com esse dualismo, e mostra que pensamentos deste tipo foram construídos por meio de estruturas (educação, sociedade, estado, igreja, etc). Mas, o interessante é que, o pós-modernismo se instala não só nas letras, mas em todas as áreas.

Aliás, o que mais pós-moderno do que desconstruir e repensar a história? Ou melhor, desconstruir a imagem que temos da história. É aqui que entra a literatura. De acordo com Linda Hutcheon (1991, p. 64) “... na ficção o termo pós-modernismo deve ser reservado para

\footnotetext{
${ }^{1}$ Primeira estrofe do poema Pecado Original, de Fernando Pessoa.
} 
descrever a forma mais paradoxal e historicamente complexa que venho chamando de 'metaficção historiográfica'." Ou seja, o pós-modernismo se efetiva na ficção por meio da metafiç̧ão historiográfica.

A história, assim como a ficção, é um construto. As figuras históricas, os nossos heróis não passam de criações humanas. Isso é o que Beatriz Sarlo deixa claro em $A$ paixão e $a$ exceção (2005, p. 96) ao mostrar como a imagem de Evita Perón foi elaborada por meio de diversos fatores. Para a autora: "O lado verídico da história importa menos do que sua transmissão e sobrevivência na mitologia evitista: Evita rainha."

Perceber a história e a literatura como construtos, carregados de subjetividade é de extrema importância para o reconhecimento das minorias. Aqueles que não encontram lugar na história oficial se abrigam na literatura (marginalizados: mulheres, negros, indígenas, pobres, homossexuais, etc). Assim, história e literatura estão intimamente ligadas e essa relação não é de oposição. Cecil Zinani comenta sobre essa importância:

Grupos minoritários que entendem a literatura a partir de outros pressupostos foram excluídos do cânone da mesma maneira que as mulheres, cuja admissão foi bastante restrita.[...] A inclusão tanto das mulheres quanto de outros grupos desprivilegiados implica a revisão do cânone o que só será possível com a reconceitualização de literatura e sua desvinculação dos mecanismos de poder ou, pelo menos, seu questionamento. (ZINANI, 2010, p. 66)

O pós-modernismo contesta a separação entre história e literatura. Essa é a grande relevância da representação histórica na literatura, pois quem detém a história possui o poder. A palavra de ordem é: questionar. E uma das formas de questionamento na 
literatura é a metaficção historiográfica. Questionar a "verdade" ²expressa na história, questionar a literatura vista como mentira, questionar as dualidades, as construções, etc.

Mas há de se deixar claro que, embora história e literatura tenham caráter subjetivo, que elas não são totalmente similares. O que as diferencia é o método, a preocupação com um mínimo de relação, seja com os fatos, seja com a realidade. A história necessita de uma relação com os fatos históricos e a literatura precisa ter um mínimo de verossimilhança. Para Clímaco (2014, p. 23) “A história segue um conjunto de práticas científicas, o que a diferencia da ficção." Desta feita, pode-se afirmar que a história é legitimada pelos documentos, a literatura não.

Ultrapassemos a teoria, vamos à prática. É sabido de todos o romance entre D. Pedro e D. Inês de Castro. Teorema narra o cruel assassinato de um dos executores de Inês e traz um ponto de vista diferente daquele expressado pela história. No conto a vítima tem por apelido Coelho, remetendo à Pedro Esteves Coelho, que de fato foi um dos três participantes da morte da amada de D. Pedro.

As figuras de D. Pedro, D. Inês, D. Constança, marquês Sá da Bandeira e o modo que Coelho foi executado são os elementos históricos. A construção da narrativa, a perspectiva de Coelho e os elementos subjetivos referem-se à ficção. De acordo com Clímaco (2014, p. 27), "A pesquisa histórica ocorre entre o dado e o criado.", e é exatamente isso que encontramos em Teorema. O dado é a história oficial do romance entre D. Pedro e D. Inês de Castro, a morte da amada e a posterior execução de seus assassinos. Já o criado no conto é a

2 A procura da verdade histórica, nessa perspectiva, torna-se utópica, pois, se história e literatura estão carregadas de subjetividade, ambas são construções. 
visão, o modo de Coelho perceber as nuances do evento de sua morte, expresso no seguinte trecho:

O rei e a amante também são criaturas infernais. Só a mulher do rei, D. Constança, é do céu. Pudera, com a sua insignificância, a estupidez, o perdão a todas as ofensas. Detesto a rainha. [...] À minha volta dizem obscenidades. Alguém sugere que me cortem o pênis. Um moço vai perguntar ao rei se o podem fazer, mas este recusa. ( HELDER, 1970, p. 95)

Esses são elementos que não constam na história oficial. Ainda de acordo com Clímaco (2014, p. 33), “... a ficção constitui um gênero literário como também o faz a história, ou seja, o discurso ficcional e o discurso histórico são gêneros discursivos, no sentido de que são elaborados na escrita." Ambas as categorias são guiadas pela subjetividade de quem as produz, enquanto o escritor utiliza sua subjetividade por meio da imaginação, o historiador utiliza-a para selecionar, pesquisar, analisar, ou seja, ambos os trabalhos estão imbricados de subjetividade.

Através do conto Teorema Herberto Helder descortina as figuras históricas e lhes confere outro aspecto: “O marquês Sá da Bandeira é que ignora tudo, verde e colonialista no alto do seu plinto de granito. As pombas voam à volta, pousam-lhe na cabeça e nos ombros, e cagam-lhe em cima" (HELDER, 1970, p. 95). Onde poderíamos encontrar essa representação do marquês Sá da Bandeira se não na literatura? A história nunca permitiria tanta ousadia.

Ao fim desta seção, é importante deixar claro algumas afirmações: História e Ficção/ Literatura são construtos humanos, repletos de subjetividade. A história está tanto na ficção, quanto a ficção está na história. Mas não são correspondentes, ou seja, apesar das semelhanças têm diferenças. A história é construída, mas essa construção precisa estar de 
acordo com os fatos. A literatura/ ficção é construída, mas precisa haver uma verossimilhança nessa construção.

\section{O PÓS-MODERNISMO DA METAFICÇÃO}

Neste segundo momento, pensarei a metaficção de Linda Hutcheon contida nas obras São Bernardo (1994) de Graciliano Ramos e A hora da estrela (1998) de Clarice Lispector. Para Hutcheon (1991, p. 63) “... o uso do termo pós-modernismo costuma se referir à metafiç̧ão, muitas vezes do tipo mais radical...", a metafiç̧ão pode ser compreendida como a reflexão da própria ficção e é isso que encontramos nas obras citadas. São Bernardo inicia com a reflexão de Paulo Honório sobre a composição do próprio livro:

Antes de iniciar este livro, imaginei construí-lo pela divisão do trabalho. Dirigi-me a alguns amigos, e quase todos consentiram de boa vontade em contribuir para o desenvolvimento das letras nacionais. Padre Silvestre ficaria com a parte moral e as citações latinas; João Nogueira aceitou a pontuação, a ortografia e a sintaxe; prometi ao Arquimedes a composição tipográfica; para a composição literária convidei Lúcio Gomes de Azevedo Gondim, redator e diretor do Cruzeiro. Eu traçaria o plano, introduziria na história rudimentos de agricultura e pecuária, faria as despesas e poria o meu nome na capa. (RAMOS, 1994, p. 5)

A obra é dividida por muitos teóricos em dois momentos: Paulo Honório narrador e Paulo Honório personagem. A metaficção pode ser encontrada no primeiro plano, ou seja, no momento em que Paulo Honório é narrador, durante o processo de reflexão de sua vida, de seus 50 anos de idade. É encontrada a metaficção apenas nos capítulos iniciais: "As pessoas que me lerem terão, pois, a bondade de traduzir isto em linguagem literária, se quiserem. Se não quiserem, pouco se perde. Não pretendo bancar escritor." (RAMOS, 1994, p. 9-10) 
Já $A$ hora da estrela (1998) é toda composta pela metaficcionalidade. Clarice Lispector rompe com todos os estereótipos narrativos. Aliás, Clarice é uma das escritoras mais pós-moderna de todos os tempos. Toda a obra é permeada de reflexões sobre o processo de escrever. Assim, a obra não tem apenas a protagonista Macabéa, mas também o próprio ato de escrever. Veja um exemplo:

Proponho-me a que não seja complexo o que escreverei, embora obrigado a usar as palavras que vos sustentam. A história- determino com falso livre-arbítrio- vai ter uns sete personagens e eu sou um dos mais importantes deles, é claro. Eu, Rodrigo S.M. Relato antigo, este, pois não quero ser modernoso e inventar modismos à guisa de originalidade. Assim é que experimentarei contra os meus hábitos uma história com começo, meio e 'gran finale' seguido de silêncio e de chuva caindo. (LISPECTOR, 1998, p. 12-13)

Enquanto narra a trajetória de Macabéa, Rodrigo S.M. nos diz como a narrativa lhe surgiu, como the transformou e como deseja que seja o final da obra. Assim como em São Bernardo, há dois planos na narrativa. O percurso de Macabéa e o processo de escritura. Mas, diferente do livro de Graciliano, a metaficção aqui perpassa toda a extensão da narrativa.

Clarice escreve e questiona, questiona e escreve. O que mais pós-moderno? Para Hutcheon (1991, p. 158) “Mais do que ambígua, a arte pós-moderna é duplicada e contraditória." Pensar A hora da estrela é percebê-la contraditória. Clarice quer dar vida à Macabéa, e como isso é feito? Através da morte, "Pois na hora da morte a pessoa se torna brilhante estrela de cinema, é o instante de glória de cada um e é quando como no canto coral se ouvem agudos sibilantes". (LISPECTOR, 1998, p. 29) 
Depois de descrever o atropelamento de Macabéa, o narrador pensa em voltar atrás em sua narrativa:

(Eu ainda poderia voltar atrás em retorno aos minutos passados e recomeçar com alegria no ponto em que Macabéa estava de pé na calçada- mas não depende de mim dizer que o homem alourado e estrangeiro a olhasse. É que fui longe demais e já não posso mais retroceder. Ainda bem que pelo menos não falei e nem falarei em morte e sim apenas um atropelamento.) (LISPECTOR, 1998, p. 80)

$\mathrm{O}$ ato de refletir sobre o processo narrativo é um ato altamente pós-moderno, pois a reflexão traz em si o questionamento. Essa metaficcionalidade nos faz refletir que o processo narrativo realmente depende das escolhas do escritor. O narrador Rodrigo S. M. examina seu processo de criação, sua forma de transpor no papel a história de Macabéa, o destino que dará à sua personagem, etc. Assim, o leitor não é apenas expectador da trajetória de Macabéa, mas também do processo de escritura de A hora da estrela.

\section{DO PROCESSO MEMORIALÍSTICO}

Neste item, será usado como amparo os teóricos José Carlos Sebe Bom Meihy ${ }^{3}$, Marcio Seligmann-Silva ${ }^{4}$ e Paul Ricoeur (1913-2005). Serão aplicados alguns conceitos destes teóricos no conto Um centurião de Graciliano Ramos.

Memória é relembrar de um fato acontecido no passado. Memória e esquecimento estão intimamente ligados, assim um não é possível sem o outro. A relação entre memória e esquecimento pode ser comparada à identidade, pois eles se formam por meio dos

3 Professor do PPG Interdisciplinar em Letras e Ciências Humanas da Universidade do Grande Rio. Professor aposentado do Departamento de História da USP, onde obteve os títulos de doutor e de livre-docente.

${ }^{4}$ Crítico literário, tradutor, teórico e professor de Teoria Literária na UNICAMP. 
antagonismos, já que, se alguém se recorda de algo é porque certamente se esqueceu de tantas outras coisas.

O processo memorialístico requer trabalho, requer exercício, mas há de se deixar claro que a memória não pode ser controlada, mas exercitada. Para Seligmann (2003, p. 83): “A memória é tão necessária e impossível quanto o esquecimento." Esse processo memorialístico afeta diretamente a história, pois esta só existe através da memória. Desta maneira, é através da memória que a subjetividade da história pode ser atestada. Portanto, a memória é o material da história, por conseguinte, sem memória não há história.

Da mesma forma que não há hierarquia entre a história e a literatura, também não há entre a memória e a história. O que existem são diferentes formas de legitimação. 0 historiador faz uma combinação, uma seleção de memória, assim o papel do historiador é o de materializar a memória. De acordo com Seligmann (2003, p. 67): “... não existe uma História neutra; nela a memória, enquanto uma categoria abertamente mais afetiva de relacionamento com o passado, intervém e determina em boa parte os seus caminhos."

A memória individual e a memória coletiva ocorrem simultaneamente, como, por exemplo, a história da família Fonseca, narrada por Sebe em Augusto e Lea: um caso de (des) amor em tempos modernos (2006). O fato comum entre todos é a doença, mas cada personagem é atingido de forma diferente pelo fato e tem uma visão distinta sobre ele.

O processo memorialístico é sempre individual, mas é necessário deixar claro que a memória individual e a memória coletiva estão intimamente ligadas, uma influi sobre a 
outra, pois, o sujeito que rememora está irremediavelmente inserido em um tempo e em um espaço.

Em Um cinturão temos a lembrança da primeira experiência do narrador com a justiça: "As minhas primeiras relações com a justiça foram dolorosas e deixaram-me funda impressão." (RAMOS, 1981, p. 32). Durante todo o relato é perceptível o esforço do narrador em lembrar-se de sua infância, mais especificamente em lembrar esse episódio fatídico em sua vida. Portanto, memória é seleção, porém não se limita à seleção dos fatos felizes, mas de igual modo dos fatos tristes. De acordo com Marcio Seligmann-Silva:

Se é verdade que no campo da memória atua a seleção dos momentos do passado e não o seu total arquivamento, ou seja, a memória só existe ao lado do esquecimento, por outro lado, cabe ao historiador- assim como individualmente a cada um de nós- não negar ou denegar os fatos do passado, mesmo os mais catastróficos. ( SELIGMANN-SILVA, 2003, p. 77)

Logo, para compor suas memórias, o narrador teve que, além de realizar seleções, fazer alguns esforços. O autor usa a expressão "Tudo é nebuloso" como forma de caracterizar o processo memorialístico, o que Paul Ricoeur chama de memória exercitada, pois é algo laborioso. Além da memória estar ligada ao esquecimento, ela também relaciona-se com a imaginação, como no seguinte trecho: "Se o pavor não me segurasse, tentaria escapulir-me: pela porta da frente chegaria ao açude, pela do corredor acharia o pé do turco. Devo ter pensado nisso, imóvel, atrás dos caixões." (RAMOS, 1981, p.33)

Para Paul Ricoeur (2007, p. 77), “A lembrança não consiste mais em evocar o passado, mas em efetuar saberes aprendidos, arrumados num espaço mental." A imaginação está a serviço da organização, pois ela serve para preencher um vazio deixado pelo tempo. O conto 
retrata cada detalhe da cena que tanto marcou a vida no narrador, mas muitos dos detalhes são frutos da imaginação, da suposição do memorialista:

Não consigo reproduzir toda a cena. Juntando vagas lembranças dela a fatos que se deram depois, imagino os berros de meu pai, a zanga terrível, a minha tremura infeliz. Provavelmente fui sacudido. O assombro gelava-me o sangue, escancarava-me os olhos. (RAMOS, 1981, p. 33)

A memória também está estreitamente ligada à identidade, mas a identidade por sua vez é construída através das relações. Rememorar também é refletir sobre si mesmo, é identificar-se. No trecho abaixo vemos que enquanto rememora seu passado, o narrador reflete sobre as consequências que esse episódio trouxe para a sua vida atual:

Situações deste gênero constituíram as maiores torturas da minha infância, e as conseqüências delas me acompanharam. [...] Onde estava o cinturão? Hoje não posso ouvir uma pessoa falar alto. 0 coração bate-me forte, desanima, como se fosse parar, a voz emperra, a vista escurece, uma cólera doida agita coisas adormecidas cá dentro. A horrível sensação de que me furam os tímpanos com pontas de ferro. (RAMOS, 1981, p. 33)

\section{CONSIDERAÇÕES FINAIS}

Por muito tempo, à história foi relegada a verdade e à literatura o caráter inventivo. $\mathrm{O}$ pós-modernismo vem com o intuito de romper com essas dicotomias excludentes e busca pensar e questionar essas estruturas. A memória, por sua vez, é o meio pelo qual a história e a literatura se igualam, ou seja, por meio da subjetividade memorialística.

Foi escolhido o poema Erro de português de Oswald de Andrade como epígrafe deste texto, pois ele traz exatamente o que se buscou refletir. A história é construída, mesmo que obedeça aos fatos ocorridos, ela é permeada por subjetividades, escolhas, análises e combinações feitas por alguém inserido em determinado tempo e espaço. 
O que temos representado no poema são os diferentes pontos de vista. Ao ler o verso passamos a questionar: O que de fato foi o "descobrimento" do Brasil? O que os livros de história sobre esse período deixaram de relatar? A colonização foi algo bom? Se sim, para quem foi bom? Esse processo histórico foi pacífico? Quem mais sofreu? São questionamentos como esses que o pós-modernismo almeja provocar.

O pós-modernismo rompe com os binarismos e permite espaço em que eles se comungam. As fronteiras não são rompidas, mas sim diluídas. Para Hutcheon (1991, p. 149), "Tanto a fiç̧ão como a história são sistemas culturais de signos, construções ideológicas cuja ideologia inclui sua aparência de autônomas e auto-suficientes." Por fim, deixamos o convite: meditemos sobre as "verdades" que nos cercam. Não só as que nos são apresentadas nos livros, mas aquelas que somos expostas no dia-a-dia. Vida e arte, ficção e história são meras construções humanas. Sejamos cientes.

\section{REFERÊNCIAS}

CLÍMACO, Adriana Ortega. História e ficção em Santa Evita. Jundiaí: Paco editorial, 2014.

HELDER, Herberto. "Teorema", in: Os Passos em Volta. $3^{\text {a }}$ ed. Editorial Estampa, 1970.

HUTCHEON, Linda. Poética do pós-modernismo: história, teoria, ficção. Tradução Ricardo Cruz.- Rio de Janeiro: Imago Ed., 1991.

LISPECTOR, Clarice. A hora da estrela. Rio de Janeiro, Rocco: 1998.

MEIHY, José Carlos Sebe Bom. Augusto e Lea: um caso de (des) amor em tempos modernos. São Paulo: Contexto, 2006.

RAMOS, Graciliano. Infância. Rio de Janeiro: Editora Record, 1981.

. São Bernardo. 60ạ ed. Rio de Janeiro: Record, 1994.

RICOEUR, Paul. A memória, a história, o esquecimento. Trad. Alein François. Campinas: Editora da Unicamp, 2007.

SARLO, Beatriz. A paixão e a exceção. São Paulo: Companhia das Letras; Belo Horizonte: Editora UFMG, 2005. 
SELIGMANN-SILVA, Marcio (org.). "Reflexões sobre a memória, a história e o esquecimento". In: História, memória, literatura: o testemunho na Era das Catástrofes. Campinas, SP: Editora da Unicamp, 2003.

ZINANI, Cecil Jeanine Albert. História da Literatura: questões contemporâneas. Caxias do Sul: RS: Educs, 2010.

Artigo recebido em: 20 de abril de 2018. Artigo aprovado em: 10 de setembro de 2018. 